\title{
PRIVILEGIOS CONCURSALES Y ACREEDORES INVOLUNTARIOS EN CUESTIONES DE SALUD
}

\section{BANKRUPTCY PRIVILEGES AND INVOLUNTARY HEALTH CREDITORS}

Nicolás Alberto Simón ${ }^{1}$

DOI: https://doi.org/10.37767/2591-3476(2020)29

\section{Comentario a}

Institutos Médicos Antártida s/ quiebra s/ inc. de verificación (R.A.F. y L.R.H. de F.)

\section{Corte Suprema de Justicia de la Nación}

\author{
Disponible en \\ https://bit.ly/3h81eFM
}

RESUMEN:

En el presente trabajo se comenta un reciente pronunciamiento de la Suprema Corte de Justicia de la República Argentina en el que, en virtud de las normas internacionales protectorias de los derechos del niño y de las personas con discapacidad, se declaró la inconstitucionalidad de ciertas normas nacionales en materia de privilegios concursales a fin de lograr el efectivo cumplimiento de una sentencia indemnizatoria de daños y perjuicios provocados en el propio alumbramiento de una persona.

\begin{abstract}
the present paper comments on a recent pronouncement of the Supreme Court of Justice of the Argentine Republic in which, due to international law protecting the rights of children and persons with disabilities, certain national bankruptcy privileges rules were declared unconstitutional in order to achieve effective compliance of a compensatory sentence of damages caused in the very birth of a person.
\end{abstract}

PALABRAS CLAVE: niño discapacitado - salud - vulnerabilidad - privilegios concursales derecho internacional.

KEY WORDS: disabled child - health - vulnerability - bankruptcy privileges - international law

\footnotetext{
1 Abogado (Universidad Nacional de Córdoba). Alumno sobresaliente promoción 2012. Especialista en derecho de daños (Universidad Castilla-La Mancha, España, 2017). Especializando en Derecho Procesal de las Ejecuciones (Universidad Blas Pascal, Córdoba). Profesor integrante de la Cátedra de Derecho Privado I (Facultad de Derecho, Universidad Siglo XXI, Córdoba). Adscripto en la Cátedra de Derecho Privado II (Facultad de Derecho, Universidad Nacional de Córdoba). Relator/Asistente de magistrado del Juzgado de Primera Instancia y Sexta Nominación en lo Civil y de la Excma. Cámara Sexta de Apelaciones en lo Civil y Comercial de la ciudad de Córdoba. Redactor del Boletín Judicial del Poder Judicial de la Provincia de Córdoba. Se desempeña como Prosecretario Letrado de la Excma. Cámara de Apelaciones en lo Civil y Comercial, Laboral, Familia y Contencioso Administrativo de la ciudad de Bell Ville, Córdoba. Mail: nicolassimon25@hotmail.com. Nro. de ORCID: https://orcid.org/0000-0002-3846-5132
} 


\section{El caso bajo análisis.}

A principios del año dos mil diecinueve, el órgano jurisdiccional de mayor jerarquía de nuestro país (Corte Suprema de Justicia de la Nación Argentina²) dictó sentencia en la causa caratulada "Institutos Médicos Antártida s/ quiebra s/ inc. de verificación (R. A. F y L. R. H. de F.) ${ }^{3}$. Un fallo novedoso en la jurisprudencia del Alto Cuerpo, no por la cuestión o materia a decidir sino por lo decidido.

A fin del análisis de la cuestión medular del pronunciamiento -inconstitucionalidad de ciertas normas del régimen de privilegios concursales dispuestos en la ley falencial $n .^{\circ}$ $24.522^{4}-$, cuadra recordar que esa causa fue iniciada por los padres de un niño discapacitado (B. M. F.) con el objeto de verificar el crédito de su hijo (indemnización de daños y perjuicios) en la quiebra de la institución médica en la que su madre fue atendida al momento del nacimiento del niño, el 25 de mayo de 1990.

A raíz de la mala praxis médica en oportunidad del alumbramiento de B. M. F., sus padres iniciaron formal demanda de daños y perjuicios en contra del médico tratante, el sanatorio "Institutos Médicos Antártida" y la obra social del Sindicato de Mecánicos y Afines del Transporte (OSMATA). El 20 de agosto de 1998, se dictó sentencia en primera instancia, condenando -en forma solidaria- a los tres codemandados a pagar cierta suma de dinero en concepto de reparación de los daños padecidos. Ese fallo fue confirmado por la Cámara de apelaciones competente con fecha 30 de mayo de 2003.

Se comprobó que, en razón de las deficientes prácticas en el alumbramiento, se le provocó a B. M. F. una parálisis cerebral con cien por ciento de incapacidad irreversible, que condujo el sufrimiento fetal agudo con afección de todos los órganos y especialmente el cerebro. Como consecuencia de ello, B. M. F. presenta, desde su nacimiento, lesiones cerebrales gravísimas con una incapacidad total e irreversible, parálisis en los cuatro miembros que le impide movilizarse y retraso en el crecimiento.

Tres meses antes de que la Cámara de Apelaciones confirmara la sentencia indemnizatoria de daños y perjuicios iniciada por los padres de aquel entonces el niño discapacitado (2003), se dictó la sentencia de quiebra del instituto médico asistencial en el cual se practicó el parto ${ }^{5}$. Transcurrieron trece años desde el nacimiento del niño totalmente incapacitado para que sus padres obtuvieran una respuesta firme del sistema judicial, para enterarse -casi de manera simultánea- que uno de sus codeudores se encontraba en estado de insolvencia económica para afrontar el pago de la indemnización debida. Indemnización que podría haber ayudado en el desarrollo y/o mejoramiento de la calidad de vida de su hijo (en aquella época, ya un adolescente).

En este panorama, los padres de B. M. F. verificaron su crédito en el proceso falencial del sanatorio (acto jurídico procesal en el marco del cual la causa llegó hasta la CSJN, pronunciamiento objeto de este trabajo) y también en la quiebra de la obra social OSMATA.

En primera instancia, el juez concursal del ente sanatorial resolvió declarar la inconstitucionalidad del régimen de privilegios previsto en los arts. 239, $1^{\circ}$ párrafo, 241, 242 parte

2 En adelante, CSJN

3 CSJN 344/2011 (47-I)/CS1. 26/03/2019.

4 En adelante, LCQ.

5 La quiebra del sanatorio "Institutos Médicos Antártida” se decretó el 10/02/2003. 
general y 243 parte general e inc. $2^{\circ}$ de la LCQ; tuvo por verificado a favor de B. M. F. un crédito con privilegio especial prioritario de cualquier otro privilegio y dispuso su pronto pago.

Apelada tal resolución por dos acreedores hipotecarios del único bien inmueble integrante de la masa concursal de la quebrada, la Sala A de la Cámara Nacional de Apelaciones en lo Comercial dispuso revocar la sentencia impugnada, entendió que el crédito de B. M. F. revestía carácter quirografario y -en consecuencia- dejó sin efecto el pronto pago establecido por el magistrado de la instancia anterior.

Ante ese decisorio, se alzaron en recurso extraordinario federal los padres de B. M. F. y la Defensoría Pública de Menores e Incapaces, recursos que fueron concedidos por ante la CSJN exclusivamente por la cuestión federal (el hecho de que la decisión de la Cámara fue contraria al derecho que los apelantes fundan en las normas internacionales de derechos humanos, de incuestionable naturaleza federal) ${ }^{6}$.

Finalmente, basándose en las normas internacionales de derechos humanos de la infancia y la discapacidad, la situación de hipervulnerabilidad de B. M. F., su necesidad de una solución urgente, el tiempo transcurrido desde el reconocimiento de la indemnización reparadora de los daños y perjuicios y la duración del trámite del incidente de verificación, la CSJN decidió -por mayoría- reconocer al crédito del incidentista un privilegio especial de primer orden en los términos recocidos por el juez concursal de primera instancia.

\section{Importancia del caso}

Como se adelantó, el fallo en comentario no es novedoso en sí por la cuestión sometida a juzgamiento sino por lo decidido en el caso en concreto.

La jurisprudencia y la doctrina nos demuestran que los casos en los cuales se pretende la modificación del orden de privilegios taxativos fijados en la ley en función de particulares situaciones de hecho, basadas en contingencias de salud, alimentarias u otras que no admitieren demoras, ya han sido planteados en nuestros estrados.

Cabe destacar que unos pocos meses antes del dictado del fallo bajo análisis, la CSJN -con distinta integración y por mayoría- resolvió un caso muy similar en sentido diametralmente opuesto. En la causa "Asociación Francesa Filantrópica y de Beneficencia s/ quiebra s/ incidente de verificación de créditos por L. A. R. y otros" ${ }^{\prime \prime}$, con el voto de la mayoría de los Ministros Elena Highton de Nolasco, Carlos Fernando Rosenkrantz y Ricardo Luis Lorenzetti, se resolvió rechazar el recurso extraordinario federal articulado por los incidentistas en la quiebra de un ente sanatorial en el entendimiento que: "(...) la preferencia que se otorgue a un acreedor respecto de los restantes en el marco de un proceso concursal es una decisión que incumbe al legislador y no a los jueces de acuerdo con las circunstancias subjetivas que en cada caso en particular se puedan plantear". ${ }^{.}$

Es más, ya en el año 2014, en el precedente "Pinturas y Revestimientos Aplicados SRL",

6 Véanse Considerandos $2^{\circ}$ y $4^{\circ}$ de la Sentencia comentada.

7 CSJN, 06/11/2018, Fallos 341:1511.

8 Véanse Considerando $17^{\circ}$, Fallos 341:1511.

9 CSJN, 26/03/2014, Fallos 337:315. 
la CSJN debió resolver -en el caso, a favor- acerca del alcance y aplicación de los privilegios de los créditos de naturaleza laboral establecidos en el Convenio 173 de la OIT en el marco de un proceso concursal nacional.

Desde la doctrina especializada se remarca: "En nuestra legislación, y en especial en materia concursal, se ha tratado desde hace largo tiempo la situación de los "menores", hoy niños y adolescentes, según las leyes 26.061 y 26.378, esta última que aprobó la Convención sobre los Derechos de las Personas con Discapacidad, que se encuentran afectados en su salud, $y$, en esta línea, la jurisprudencia ha ido avanzando en el sentido de otorgarles un trato "preferencial", aun cuando no existe norma concreta que así lo disponga"mo.

Sabido es que uno de los principios troncales del derecho concursal es el de la igualdad de trato de los acreedores, conocido en términos latinos con el principio "pars condicio creditorum". Esta regla significa que en la base del proceso concursal se encuentra la "justicia distributiva" que exige la satisfacción de todos los acreedores, de conformidad a la naturaleza de su crédito y no la "justicia conmutativa" de las relaciones sinalagmáticas".

Como implicancia de ese principio, los acreedores del deudor fallido participan en la distribución del producido de la liquidación de los bienes de este último en igualdad de condiciones, salvo expreso privilegio previsto en la ley concursal.

El art. 2573 del Código Civil y Comercial ${ }^{12}$, vigente en nuestra nación desde el 01 de agosto de 2015 , define a los privilegios como la calidad que corresponde a un crédito de ser pagado con preferencia a otro.

Conforme una postura positivista a ultranza, los privilegios únicamente pueden ser creados por ley (art. 2574 del CCCN) y son de interpretación restrictiva.

Según lo dispuesto en el art. 239 de la LCQ, el régimen de privilegios concursales es autosuficiente. El art. 2579 del CCCN ratifica este criterio en cuanto prevé que en los procesos universales los privilegios se rigen por la ley aplicable a los concursos, exista o no cesación de pagos. Ello quiere decir que las preferencias de pago o privilegios previstos en leyes distintas a la concursal se aplican exclusivamente en los procesos de ejecución individuales, salvo remisión expresa de la ley concursal a esos ordenamientos ajenos a ella.

De allí, la trascendencia de este pronunciamiento de la Corte. El fallo merece su estudio no sólo en razón de la autoridad moral del órgano jurisdiccional del que emana sino también porque, basándose en normas de derecho internacional de rango constitucional y protectoras de los derechos de niños y niñas y personas con discapacidad, la Corte Federal se expidió respecto de la ardua y difícil discusión abierta en torno a la preferencia de cobro de los llamados "acreedores involuntarios por cuestiones de salud" en el marco de un proceso falencial.

10 JUNYENT BAS, Francisco A. y MARCOS, Fernando J., "Los privilegios concursales frente a la vulnerabilidad del "acreedor involuntario"', LA LEY 27/02/2019, 27/02/2019, p. 3, Cita Online: AR/DOC/187/2019.

11 JUNYENT BAS, Francisco A.; MOLINA SANDOVAL, Carlos A., "Ley de Concursos y Quiebras - Comentada”, Abeledo-Perrot, $3^{\circ}$ ed., Buenos Aires, 2011, t. I, p. 29.

12 En adelante, $\mathrm{CCCN}$. 


\section{III. ¿Quiénes son los acreedores involuntarios del concurso? Su relación con el "sú- per pronto pago"}

En primer lugar, es dable resaltar que la respuesta a ese interrogante no se encuentra en el texto de la ley falencial nacional. Los autores y los magistrados especializados son quienes han delineado su noción.

Al comentar el fallo "Asociación Francesa Filantrópica y de Beneficencia s/ quiebra s/ incidente de verificación de créditos por L. A. R. y otros", Francisco Junyent Bas y Fernando Marcos señalan que la CSJN "se refirió al régimen de privilegios en el concurso frente al crédito de un acreedor que se encuentra en una situación de extrema vulnerabilidad; rectius: un acreedor involuntario que peticiona el reconocimiento para su acreencia de una preferencia de pago que la legislación concursal vigente no le acuerda en forma expresa"m3.

Por su parte, Maurico Boreto, al analizar el fenómeno de la constitucionalización del derecho privado y su influencia en el ámbito del derecho concursal nacional, reconoce la figura del acreedor falencial involuntario como una aplicación práctica de aquel fenómeno. El autor refiere que los acreedores involuntarios o acreedores extracontractuales son aquellos "(...) que se han visto afectados por infortunios personales u otros daños cuyo autor ha sido el deudor concursado y que -pese a la urgencia en obtener las prestaciones correspondientes por razones de salud, alimentarias $u$ otras que no admiten demoras- deben enfrentar las quitas, esperas y los "tiempos muertos" del proceso concursal. En suma, quedan comprendidos todos aquellos acreedores que no están vinculados con el deudor por vínculos negociales o contractuales y que se encuentren en situación de urgencia (...)"; y con precisión, realismo fáctico y jurídico, agrega: "La piedra de la discordia ha sido que la jurisprudencia les ha otorgado a estos acreedores -sin norma concursal expresa en que sustentarse- un tratamiento "privilegiado" (pese a no hallarse en el elenco de acreedores con privilegio enumerados en la ley 24.522), concediéndoles el derecho de pronto pago a créditos que no se encontraban investidos legalmente de esa prerrogativa para su percepción anticipada; soslayando, de esa manera, la pars condicio creditorum y los términos de la propuesta de acuerdo preventiva dirigida a los quirografarios ${ }^{14}$.

Desde una perspectiva clásica, el pronto pago concursal se define como una vía sumaria de verificación del crédito de naturaleza laboral que constituye una tutela especial destinada a que los trabajadores no se vean forzados a esperar el trámite de la quiebra o del concurso preventivo para cobrar su crédito, a mérito del carácter alimentario de este último.

En la LCQ, la figura del pronto pago está expresamente prevista en los arts. 16 (concurso preventivo) y 183 (quiebra).

Existen tres modalidades de pronto pago según nuestro ordenamiento nacional: el pronto pago de oficio por parte del juez concursal, el pronto pago a pedido de parte y el "súper pronto pago". Sus requisitos y procedimientos escapan los límites de este trabajo, no obstante lo cual considero necesario y oportuno recordar algunos puntos de la última modalidad referida.

El párrafo onceavo del art. 16 de la LCQ, que establece lo que se conoce como el "súper pronto pago", reza: "Excepcionalmente el juez podrá autorizar, dentro del régimen de pronto

13 JUNYENT BAS, Francisco A. y MARCOS, Fernando J. (2019): Op. cit. p. 4.

14 BORETTO, Francisco, "El fenómeno de la "Constitucionalización" del derecho privado en la Argentina y su impacto en el ordenamiento jurídico falencial", RDCO 256, 01/09/2012, 341, p. 4, Cita Online: AR/DOC/9455/2012 
pago, el pago de aquellos créditos amparados por el beneficio y que, por su naturaleza o circunstancias particulares de sus titulares, deban ser afectados a cubrir contingencias de salud, alimentarias u otras que no admitieran demoras".

Se discute en doctrina si esa potestad del magistrado comercial de autorizar el pago de créditos urgentes se circunscribe exclusivamente a aquellos de naturaleza exclusivamente laboral (postura restrictiva) o si también puede responder a otros derechos fuera de los contemplados y protegidos por el derecho del trabajo (postura amplia).

No caben dudas que, en el caso bajo análisis, el juez de primera instancia que resolvió el incidente de verificación de créditos incoado por los padres de B. M. F. (como así también la mayoría de los miembros de la CSJN), ordenó el pronto pago del crédito indemnizatorio, alistándose en aquellos que propugnan la tesis amplia. Recuérdese que el crédito verificado en la quiebra del Instituto Antártida tenía como causa fuente la responsabilidad civil del ente sanatorial por la mala praxis médica en el parto de B. M. F.

Luego de declarar la inconstitucionalidad de las normas concursales pertinentes del régimen de privilegios, para así otorgar rango preferente especial a la acreencia de B. M. F., el juez del concurso tuvo en especial consideración el carácter urgente que revestía la indemnización reconocida. Esa indemnización hacía a la propia persona, a su fortalecimiento, a su dignidad, al propio sustento de la vida misma. No cabía otra solución que la adoptada. Si la naturaleza de ese crédito, luego de años y años de transitar pasillos tribunalicios, no implicaba un "súper" pronto pago, entonces surge la pregunta: ¿qué tanto más se requería para lograr ese pago urgente?, o mejor dicho ¿qué tanto más debía perder B. M. F. para poder vivir?

\section{Los votos.}

La Corte resuelve este caso con una integración "particular" en comparación con la que -unos casi cinco meses antes- había sentenciado en los autos "Asociación Francesa Filantrópica y de Beneficencia s/ quiebra s/ incidente de verificación de créditos por L. A. R. y otros". Debido a la excusación del Ministro Carlos Fernando Rosenkrantz, el máximo tribunal que estudió y decidió esta causa estuvo compuesto por los Dres. Elena Highton de Nolasco, Ricardo Luis Lorenzetti, Juan Carlos Maqueda, Horacio Rosatti y Graciela Medina.

La mayoría -compuesta por los votos de los Dres. Rosatti, Maqueda y Medina- votó a favor de la procedencia del recurso extraordinario articulado por los padres de B. M. F., mientras que los Dres. Highton de Nolasco y Lorenzetti se pronunciaron en igual sentido al voto emitido al resolver la causa "Asociación Francesa", es decir por el rechazo del recurso y la consecuente confirmación de lo decidido por la Cámara de apelaciones.

No puede negarse que esa "particular" conformación de la CSJN (y la mayoría obtenida) pueda llegar a generar cierta incertidumbre respecto de cuál será el criterio del tribunal en los casos venideros a resolver respecto del orden de los privilegios concursales mediado un acreedor involuntario. De hecho, desde la doctrina esa cuestión ya está planteada y genera distintas miradas ${ }^{15}$. 
Sin embargo, ello no quita trascendencia al resolutorio comentado. Su importancia es notable, no sólo como precedente jurisprudencial del tribunal superior de la nación sino -en mi humilde opinión- como pronunciamiento concreto para la persona de B. M. F. Es un verdadero ejemplo de búsqueda de legitimación social del Poder Judicial como institución, un fallo acorde al derecho internacional y constitucional que golpea fuerte al ritualismo, las normas estancas y al statu quo.

Las palabras finales del voto de la Sra. Conjueza, Dra. Graciela Medina, reflejan mi sentir: "(...) no puedo dejar de expresar el profundo dolor que siento como mujer de derecho y magistrada, al ver que este joven, ha transitado toda su niñez, su adolescencia y parte de su vida adulta, esperando una respuesta judicial definitiva que no llega, mientras su salud se deteriora. Tengo claro que la intervención de este Tribunal, no ha sido más que otro escalón en un larguísimo proceso, pero eso no hace que me sienta menos mal. Todos los operadores judiciales deberíamos sentarnos unos momentos a reflexionar sobre este tipo de situaciones y replantearnos el rol de cada uno, para evitar que se repitan. Ojalá este pronunciamiento lleve un poco de paz a la víctima y a sus familiares, y contribuya a que pueda obtener la mejor calidad de vida posible por el resto de su existenciam6.

\section{Puntos destacables. La mayoría.}

A continuación, resumiré los principales argumentos en los que se basó la decisión adoptada por la mayoría.

No debe perderse de vista que los Dres. Rosatti, Maqueda y Medina votaron en clave de derechos humanos. La visión de derecho internacional de sus votos es evidente. De no haber sido así, el régimen taxativo, legal y exhaustivo de los privilegios concursales establecidos en el derecho interno hubiese ganado la batalla.

Esos tratados internacionales que, desde la reforma constitucional del año 1994, cuentan con jerarquía constitucional (art. 75, inc. 22 de la Constitución Nacional) establecen el derecho de toda persona a gozar de un nivel adecuado de vida y al disfrute del más alto nivel posible de salud. De manera sucinta, el pronunciamiento de la Corte hace referencia a la Declaración Universal de Derecho Humanos (art. 25), al Pacto Internacional de Derechos Económicos, Sociales y Culturales (art. 11 y 12), a la Convención América sobre Derechos Humanos (art.19), a la Convención sobre los Derechos del Niño (arts. 3.1, 23.1, 24, 27.1 y 27.3) y a la Convención sobre los Derechos de las Personas con Discapacidad (arts. 7, aps. 1 y $2,10,12,25$ y 28.1).

Destaco el art. 24.1 de la Convención sobre los Derechos del Niño ${ }^{17}$ y el art. 8.1 de la Convención sobre los Derechos de las Personas con discapacidad ${ }^{18}$. Considero que la conjunción de estas dos normas internacionales, de jerarquía superior a la ley de concursos y quiebras nacional, sienta la naturaleza y el sentido de la resolución del Alto Cuerpo nacional.

El art. 24.1 de la CDN reza: "Los Estados Partes reconocen el derecho del niño al disfrute

\footnotetext{
deber de proteger a los sujetos vulnerables", SJA 22/05/2019, 22/05/2019, 32 - DFyP 2019 (junio), 28/06/2019, 215 - DFyP 2019 (agosto), 08/08/2019, 172, Cita Online: AR/DOC/1301/2019.

16 Véase Considerando $20^{\circ}$ del voto de la Dra. Medina.

17 En adelante, $\mathrm{CDN}$.

18 En adelante, CDPD.
} 
del más alto nivel posible de salud y a servicios para el tratamiento de las enfermedades y la rehabilitación de la salud. Los Estados Partes se esforzarán por asegurar que ningún niño sea privado de su derecho al disfrute de esos servicios sanitarios".

Por su parte, el art. 8.1 de la CDPD establece: "Los Estados Partes se comprometen a adoptar medidas inmediatas, efectivas y pertinentes para: a) Sensibilizar a la sociedad, incluso a nivel familiar, para que tome mayor conciencia respecto de las personas con discapacidad y fomentar el respeto de los derechos y la dignidad de estas personas (...)".

Sin perjuicio de ser reiterativo, repito que nos encontramos en el marco de un proceso de verificación de un crédito indemnizatorio precisamente del bien jurídico "salud". La indemnización de daños y perjuicios fue reconocida a favor de B. M. F. debido a un hecho que marcó toda su vida: una mala praxis en su mismo comienzo, el parto.

Fue tanto el impacto de esa mala praxis en la vida y dignidad de la persona de B. M. F. que se comprobó que, luego de transitar veintiocho años de una incapacidad total, la insuficiencia de tratamientos médicos adecuados -derivada, entre tantos factores, de la falta de recursos económicos de sus padres- agravó considerablemente su cuadro clínico. De la letra del fallo se extrae que, al dictado de la sentencia de la Corte, B. M. F. padecía una condición de cuadriplejia irreversible, pérdida de la visión y del habla, necesidad de ser alimentado con sonda gástrica y recurrentes complicaciones como trombosis, escaras y anemia.

A ese cuadro de deficiente salud se le suma la "situación de ahogo económico" (términos textuales de la CSJN) de sus padres. La madre de B. M. F. se dedica exclusivamente al necesario cuidado de su hijo discapacitado, y su padre, único sostén económico del hogar, había perdido su trabajo hacía cuatro años.

En ese panorama, la CSJN entendió la extrema situación de vulnerabilidad del justiciable y actuó conforme al derecho internacional incorporado a nuestra Constitución. De no haber sido así, me pregunto: ¿Cómo se cumpliría la manda de garantizar el derecho del niño discapacitado (hoy adulto) al disfrute del más alto nivel posible de salud (art. 24.1 de la CDN), cuando el único bien de la quiebra de su deudor -del cual pueden cobrar su acreencia- está gravado con dos hipotecas que tienen preferencia de pago según la ley nacional?

El Poder Judicial, como representante del estado nacional, debía adoptar una medida inmediata, efectiva y pertinente del respeto de los derechos y la dignidad de B. M. F (art. 8.1 de la CDPD). Entonces, se plantea el siguiente interrogante: ¿reconocer que la acreencia de B. M. F tiene un privilegio especial, y que por lo tanto, debe pagarse de manera preferencial y pronta frente a las demás obligaciones del fallido, no es la manera más inmediata, efectiva y pertinente que el derecho nacional confiere para cobrar lo debido? Tramitándose la causa por ante la CSJN, se alegó que todos los deudores solidarios (en realidad, concurrentes) del justiciable se encontraban en estado de insolvencia y se tuvo especial ponderación al hecho de que el activo de la quiebra no alcanzaría ni siquiera a satisfacer los créditos quirografarios. Dos puntos más que, sumados al hecho de que los problemas en la salud del niño se plantearon desde el mismo momento de su nacimiento, que desde esa fecha vive con una incapacidad total y que no contó ni cuenta con el apoyo económico suficiente de sus representantes, hacen que la vulnerabilidad del incidentista alcance límites impensados. 
Esa excepcionalidad de la situación fáctica del caso concreto traído a resolver constituyó un extremo dirimente para el Alto Cuerpo.

Se sostuvo: “(...) dadas las particularidades que presenta el caso, resulta imperativo ofrecer una satisfactoria protección jurídica de la vida y de la salud del incidentista, que sea respetuosa de la dignidad que es inherente al ser humano y que no signifique una demora que desnaturalice y torne ilusoria la reparación del derecho irreversiblemente dañadom9.

Al comentar el fallo de primera instancia dictado por el juez concursal de la causa, el maestro Francisco Junyent Bas señaló: “(...) los incidentistas han introducido, con inteligencia, desesperación o ambas, una visión prioritariamente constitucional de su reclamo, que fuerza a un análisis del cual nunca debería claudicarse"; y nos recuerda que aquel "(...) juzgador lamenta que el legislador nacional no haya advertido la especialidad del derecho del menor discapacitado que no puede ser preterido por créditos patrimoniales, ni aun por los privilegios especiales, sean de carácter real o laboral. Así el doctor Eduardo Malde (Juez concursal de primera instancia) afirma, sin hesitación, que toda acción u omisión que se oponga al interés superior del niño y a la protección de su salud, constituye un acto contrario a sus derechos fundamentales, de conformidad al art. 5 de la ley 26.061"20.

La vida de las personas es el primer derecho reconocido y protegido por la ley fundamental. Sin un nivel adecuado de salud, el derecho a la vida se debilita.

El voto de la mayoría demuestra ese razonamiento. La CSJN resuelve el caso centrándose en la persona y dignidad de un sujeto gravemente dañado en su salud.

Asimismo, el Tribunal advierte la diferencia esencial en el marco legal internacional aplicable al caso con aquel de la causa "Pinturas y Revestimientos Aplicados S.A.". Los tratados de derechos humanos citados no contemplan expresamente el carácter privilegiado de la indemnización de daños a la salud de un niño o niña. Tampoco lo hacen los convenios internacionales referidos a la protección de las personas con discapacidad, como sí lo contempla el tratado de la Organización Internacional del Trabajo n. ${ }^{\circ} 173$.

No obstante ello, entiende: "Si bien es cierto que el privilegio contemplado en la Ley de Concursos y Quiebras es una excepción al principio de paridad que rige entre los acreedores de un mismo deudor, que solo puede resultar de una disposición legal, en el caso se presenta una situación excepcional de absoluta vulnerabilidad que este Tribunal no puede desatender en orden a las exigencias de los tratados internacionales citados".

No debe olvidarse que los tratados de derechos humanos incorporados en el art. 75, inc. 22, de nuestra Constitución Nacional tienen rango superior a las leyes de la nación y que los compromisos asumidos por los estados a través de su firma y ratificación no pueden ser desatendidos en razón de las normas del derecho interno.

El art. 27 de la Convención de Viena sobre el derecho de los tratados, ratificada por la República Argentina por ley n. ${ }^{\circ} 19865$ del 3/10/1972, establece que un estado parte no podrá invocar las disposiciones de su derecho interno como justificación del incumpli-

19 Véase Considerando n. ${ }^{\circ} 20$ del fallo comentado.

20 JUNYENT BAS, Francisco, "Se abrió el cielo. A propósito de los daños a la salud del menor y la inconstitucionalidad del régimen de privilegios concursales", LA LEY 24/09/2007, 24/09/2007, 5, - LA LEY2007-E, 552, p. 2 y 5, Cita Online: AR/DOC/2741/2007. 
miento de un tratado. Por consiguiente, si desde el derecho internacional incorporado a la Constitución se establece que el estado argentino debe garantizar el mejor y más alto nivel de salud de un niño o de una persona discapacitada, y el ordenamiento legal interno ni siquiera reconoce un privilegio general al crédito indemnizatorio de salud de una persona en situación de extrema vulnerabilidad, pues entonces se verifica una inconsistencia que debe ser superada.

Indiscutido es que al legislador nacional le corresponde superar esa anomalía o vacío legislativo, y sancionar una regla abstracta, impersonal y de aplicación general. Ahora bien, si no lo hace -o ya no lo hizo, como en el caso estudiado-, el Poder Judicial debe dar una respuesta acorde. En la extrema situación de salud de B. M. F., esa respuesta acorde no era otra que la declaración de inconstitucionalidad de las normas del régimen nacional de privilegios concursales.

El control de constitucionalidad de oficio es un deber de la magistratura impuesto por el principio iura novit curia, respecto del cual el control de convencionalidad es un parámetro fundamental. Este último es un proceso dirigido a desentrañar y fijar el sentido de la norma internacional, contenida en cualquier instrumento que resulte obligatorio para el Estado argentino, con la finalidad de verificar la adecuación y ajuste de la aplicación de la norma interna respecto de aquella ${ }^{21}$. Por ello, la decisión de juez concursal de primera instancia, ratificada por la Corte Federal, confirma que toda acción u omisión al interés superior del niño y a la protección de su salud constituye un acto contrario a los derechos humanos fundamentales de carácter constitucional.

Además, citando algunos de sus precedentes, la Corte recuerda que: “(...) la Constitución Nacional -y los instrumentos internacionales incorporados a ella- asume el carácter de una norma jurídica y, en cuanto reconoce derechos, lo hace para que estos resulten efectivos y no ilusorios, sobre todo cuando se encuentra en juego un derecho humano fundamental'n2. Ello denota que la protección internacional acordada a la dignidad y a la salud de los niños, niñas y personas con discapacidad importa una norma vinculante, operativa y con perspectiva de no regresividad que ameritaba la decisión tomada.

Por último, no puedo omitir que, en sus medulosos votos, los Dres. Medina y Rosatti también analizaron la eventual responsabilidad internacional del estado argentino en caso de tomarse una decisión distinta.

La Dra. Medina señaló: "(...) la obligación que los tratados de derechos humanos imponen a los Estados Parte, alcanza a todos aquellos que se encuentren bajo su jurisdicción, tal como se ha planteado en distintas Observaciones Generales de los distintos Comités de seguimiento de los Tratados Internacionales en la materia, que constituyen los intérpretes autorizados de cada uno de los respectivos pactos en el plano internacional y cuya interpretación debe ser tenida en cuenta ya que comprende las "condiciones de vigencia" de esos instrumentos internacionales que poseen jerarquía constitucional en los términos del art. 75, inc. 22 de la Constitución Nacional (Fallos: 332:709)”23; y por su parte, el Dr. Rosatti dijo: “(...) la Convención sobre los Derechos del Niño y la Convención sobre los Derechos de las Personas con Discapacidad

\footnotetext{
21 Para mayor abundamiento, véase PALACIO DE CAEIRO, Silvia B., "Constitución Nacional en la doctrina de la Corte Suprema de Justicia de la Nación”, La Ley, Bs.As., 2011, p. 87 y ss.

22 Véase Considerando $\mathrm{n}^{\circ} 14$ del fallo comentado.

23 Véase Considerando n. ${ }^{\circ} 15$ del Voto de la Dra. Medina.
} 
reconocen que los niños discapacitados se encuentran en una situación de particular vulnerabilidad, lo que demanda una protección especial de parte del Estado, la familia, la comunidad y la sociedad, y estas obligaciones reforzadas tienen por fin garantizar que aquellos gocen de los derechos humanos fundamentales reconocidos en esos instrumentos y en el resto de las normas nacionales e internacionales. La Convención Americana sobre Derechos Humanos, por su parte, recepta la misma consideración al establecer que los niños tienen derecho a medidas especiales de protección, esto es, medidas que su condición de menor requieran por parte de su familia, de la sociedad y del Estado"24.

En este caso en particular, el Poder Judicial -actor en nombre de la República Argentinano podía mantener la validez del régimen nacional de privilegios concursales, y de esa manera permitir que los acreedores hipotecarios del ente sanatorial cobraran su crédito con anterioridad a B. M. F., so pena de incurrir en un acto reprochable en la comunidad internacional.

Las decisiones jurisdiccionales de los jueces pueden ser fuente directa de responsabilidad estatal internacional. Sentenciar en clave de derechos humanos es hoy -y desde hace ya varios años- un deber funcional y constitucional de los magistrados.

Entonces, para reconocer el carácter privilegiado y prioritario del crédito indemnizatorio de B. M. F. era menester descartar por inconstitucional la aplicación del art. 239, primer párrafo, de la LCQ. En un mar tan peligroso y fatalista, no se avizora otro puerto más seguro que el de la Antártida.

\section{Algunas consideraciones en torno al voto de la minoría.}

A tenor que la cuestión propuesta fue sustancialmente análoga a la debatida y resuelta en la causa "Asociación Francesa", los Dres. Highton de Nolasco y Lorenzetti refirieron a las conclusiones allí expuestas, por razones de brevedad.

En resumidas palabras, su postura se basó en los siguientes argumentos:

a. Las Convenciones sobre los Derechos del Niño y sobre los Derechos de las Personas con Discapacidad consagran un mandato general de mayor protección constitucional que implica obligaciones a cargo del Estado, lo que no autoriza a reconocer judicialmente un privilegio a un crédito quirografario. Además, los tratados internacionales no prevén ni determinan en qué ámbitos y con qué alcance se hará efectiva esa especial protección, la que queda reservada entonces a cada uno de los Estados.

A ese lineamiento argumental puede contestarse que si bien es cierto que el estado, al firmar y ratificar un tratado internacional, es el responsable principal y directo en caso de incumplimiento de sus cláusulas, no debe perderse de vista que el Poder Judicial constituye ese estado y que, sus decisiones -junto a la de los otros poderes institucionalespueden acarrear responsabilidad ante la comunidad internacional.

Luego de efectuar el test de convencionalidad y advertir -por parte del magistrado de primera instancia y, luego, por la propia CSJN- que el régimen de privilegios concursales se encontraba reñido con las normas internacionales de protección de los derechos del niño y de las personas con discapacidad en este caso en particular, se decidió declarar la 
inconstitucionalidad de las normas nacionales y otorgar preferencia de cobro al crédito de extrema urgencia y necesidad del incidentista. El Juez no sólo hizo eso. De hecho, integró el derecho y "Ilenó" la laguna jurídica existente, al establecer el asiento de ese privilegio especial en los bienes del establecimiento sanitario donde B. M. F. fue atendido y afectado.

La decisión se tomó para el caso en concreto. Y la misma fue tan atinada -tanto desde el valor justicia como desde tecnicismo jurídico- que, al resolver, la Corte hizo expresa referencia a los términos de la sentencia del juez concursal. La Corte dijo: "(...) atento a la citada situación de vulnerabilidad (...) que requiere de una solución que la atienda con urgencia, al tiempo transcurrido desde el reconocimiento del crédito por los daños y perjuicios sufridos, y a la duración que tuvo el trámite del presente incidente de verificación, corresponde que este Tribunal (...) ponga fin a la discusión en examen y fije para el crédito de B.M.F. el privilegio especial de primer orden en los términos en que fue reconocido por el juez de primera instancia".

b. Romper el régimen legal de privilegios y crear un sistema paralelo, contra legem, discrecional y casuístico puede conllevar un fuerte impacto negativo para la seguridad jurídica en general y podría afectar los derechos de terceros acreedores, que también pueden ser titulares de derechos alimentarios.

Considero que en virtud de lo decidido, la CSJN “no rompió" el régimen de los privilegios establecidos en la ley nacional concursal. Ello hubiera acontecido en el supuesto en que se hubiese modificado la propia ley que establece el régimen actual de preferencias de pago, cuestión que -constitucionalmente- no podría suceder conforme nuestro sistema de división institucional de poderes, mediante el dictado de un acto de decisión del Poder Judicial.

Se falló para este caso en concreto en función de las excepcionalísimas condiciones de urgencia y necesidad del incidentista.

Según sentados criterios de control de constitucionalidad y convencionalidad, todo magistrado debe efectuar ese test en un caso en concreto y siempre que la ofensa y repugnancia de la ley con el bloque de constitucionalidad sea grave, manifiesta y patente. Esos presupuestos fueron verificados en la causa, lo que importó que el tribunal de justicia no aplicara cierta norma en ese caso en particular.

Reitero, con este pronunciamiento la CSJN ha sentado un importante precedente que conforme nuestro sistema constitucional y legal vigente, no importa una modificación general y abstracta de la normativa de privilegios concursales a aplicar en casos venideros.

No obstaste ello, la sentencia dictada demuestra una realidad: debido a la proliferación de casos como el resuelto, en la República Argentina se requiere una revisión del orden legal de privilegios concursales que contemple al acreedor involuntario ${ }^{25}$.

Esa laguna jurídica del derecho concursal interno, en disonancia con el derecho internacional, también importó afectación de los derechos de los demás acreedores de la fallida

25 Repárese que, en países como España y Estados Unidos, la situación de los acreedores involuntarios ya tiene consagración legal expresa. Al efecto, véase BORETTO, Mauricio (2012), Ob. Cit. p. 5. 
en lo que respecta a la seguridad jurídica. B. M. F. logró tener un pronunciamiento firme respecto de la preferencia de cobro de su acreencia después de litigar -en sede concursal- por mucho más de diez años, tiempo en el que los acreedores hipotecarios del ente sanatorial quebrado tampoco pudieron hacerse de su crédito. Si el derecho interno hubiese tenido una norma expresa que contemplara el privilegio (general o especial) del crédito de los acreedores involuntarios -tal como lo pregona cierta doctrina-, la solución del litigio hubiese sido más pronta para todos los interesados.

c. Las normas de las convenciones internacionales que tutelan a niños y personas con discapacidad están dirigidas al Estado, para que implemente las políticas públicas necesarias para cumplir tales fines. El Poder Judicial no debe sustituir al legislador a la hora de fijar en qué ámbitos debe efectivizarse aquella mayor protección constitucional, o decidir qué políticas públicas deben implementarse en materia de protección de la niñez o de la discapacidad.

Al fallar el caso, la CSNJ no se arrogó -con carácter permanente ni de manera absolutapotestades privativas del poder legislativo. Resolvió un caso según normas de contenido supralegal incorporadas a nuestra Constitución Nacional.

Esas mismas normas que obligan al estado argentino a adoptar medidas positivas y eficientes para el logro de los derechos y prerrogativas consagrados en sus textos.

La propia Corte ha dicho: “(..) los menores, máxime en circunstancias en las que se encuentra comprometida su salud y su normal desarrollo, a más de la especial atención que demandan de quienes están directamente obligados a su cuidado, requieren también a de los jueces y de la sociedad toda"26 ¿Qué otra medida más eficaz podría haberse tomado, sin incurrir en una eventual responsabilidad internacional por no haber aplicado el derecho incorporado a nuestra Constitución?

\section{Reflexión final.}

Los acreedores involuntarios del proceso concursal llegaron a la Corte. El derecho internacional de los derechos humanos continúa inmiscuyéndose en campos en los que unos años atrás era impensada su influencia. La sociedad sigue moviéndose, y el orden jurídico parece alcanzarla.

El fallo comentado sienta un gran precedente de la Corte Suprema de Justicia de la Nación, una sentencia que -por mayoría- procura acercar la justicia al caso en concreto; una resolución que se aleja de una férrea postura exclusivamente patrimonial para centrarse en la dignidad de la persona del justiciable.

Resta aún transitar un largo camino. Siguiendo a Junyent Bas y Marcos, "hasta tanto el legislador asuma su deber y tome cartas en este delicado asunto sobre los derechos patrimoniales de quienes se encuentren en estado de extrema vulnerabilidad y sobre la preferencia de cobro de sus créditos ante la insolvencia del deudor, sólo va a encontrar cierto cauce y contención a partir del análisis de cada caso, sin que el excepcional corrimiento del régimen legal taxativo de los privilegios -ratificado como tal por el codificador del año 2015- se deba interpretar como la desaparición del régimen de numerus clausus que regía y rige la temática de los privilegios ${ }^{\prime 27}$. 
Las obligaciones nacen para ser cumplidas, y si el plexo de derechos humanos incorporados a la Constitución Nacional otorga especial protección a créditos que hacen a la dignidad de los niños y niñas y de las personas con discapacidad, ni el derecho concursal ni ninguna otra rama de la legislación nacional debe hacer oídos sordos a aquellas mandas.

\section{REFERENCIAS BIBLIOGRÁFICAS}

- BORETTO, Francisco, "El fenómeno de la "Constitucionalización" del derecho privado en la Argentina y su impacto en el ordenamiento jurídico falencial", RDCO 256, 01/09/2012, 341, Cita Online: AR/DOC/9455/2012.

- JUNYENT BAS, Francisco, "Se abrió el cielo. A propósito de los daños a la salud del menor y la inconstitucionalidad del régimen de privilegios concursales", LA LEY 24/09/2007, 24/09/2007, 5, - LA LEY2007-E, 552, Cita Online: AR/DOC/2741/2007.

- JUNYENT BAS, Francisco A. y MARCOS, Fernando J., "Los privilegios concursales frente a la vulnerabilidad del "acreedor involuntario"', LA LEY 27/02/2019, 27/02/2019, Cita Online: AR/DOC/187/2019.

- JUNYENT BAS, Francisco A.; MOLINA SANDOVAL, Carlos A., "Ley de Concursos y Quiebras

- Comentada", Abeledo-Perrot, $3^{\circ}$ ed., Buenos Aires, 2011.

- OLMO, Juan Pablo y SCASSERRA, Selene I., "Mezcla rara de infancia, discapacidad, privilegios concursales, acreedores involuntarios y conjueces. ¿Qué justicia queremos?", SJA 22/05/2019, 22/05/2019, 19. Cita Online: AR/DOC/1439/2019;

- PALACIO DE CAEIRO, Silvia B., “Constitución Nacional en la doctrina de la Corte Suprema de Justicia de la Nación", La Ley, Bs.As., 2011.

- RIBERA, Carlos E., "El acreedor involuntario con privilegio especial", LA LEY 12/04/2019, 12/04/2019, 5 - LA LEY2019-B, 290 - DFyP 2019 (mayo), 10/05/2019, 147. Cita Online: AR/ DOC/835/2019.

- YUBA, Gabriela, "El Estado y el deber de proteger a los sujetos vulnerables", SJA 22/05/2019, 22/05/2019, 32 - DFyP 2019 (junio), 28/06/2019, 215 - DFyP 2019 (agosto), 08/08/2019, 172, Cita Online: AR/DOC/1301/2019. 